\title{
Karadeniz Ekonomik İşbirliği Örgütü Ülkelerinde Enerji Tüketimi ve Ekonomik Büyüme illişkisi: Panel Nedensellik Analizi*
}

\author{
The Relationship Between Energy Consumption and Economic Growth in \\ BSEC Countries: Panel Causality Analysis
}

\author{
Yrd. Doç. Dr. Zafer Öztürk - Arş. Grv. Damla Öz
}

\begin{abstract}
Öz
Karadeniz Ekonomik İşbirliği Örgütü 1992 yılında Türkiye öncülüğünde kurulmuştur. On iki üyesi olan bu oluşumun temel amacı hem ekonomik hem de politik ilişkileri küresel ve bölgesel düzeyde artırmaktır. Enerji havzası ve koridoru üzerinde bulunan bu ülkelerde sanayi sektörünün temel girdilerinden biri olan enerji ile ekonomik büyüme arasındaki ilişkinin analizi uygulanacak enerji politikalarm da etkileyecektir. Bu çalışmada Karadeniz Ekonomik İşbirliği Örgütüne üye ülkelerde ekonomik büyüme ile enerji tüketimi arasındaki ilişki panel nedensellik metoduyla analiz edilmiştir. Bu amaçla, Konya (2006) tarafindan geliştirilen yatay kesit bağımlilı̆ııı ve modeldeki değișen varyansl hata terimi durumlarm hesaba katan panel SUR nedensellik testi kullanılmıştır. Çalışmada Dünya Bankası veri tabanı WDI'dan elde edilen yıllık kişi başına reel GSYH ve kişi başına enerji tüketimi verileri kullamılmıştır. Veriler 1992-2011 yılları arasını kapsamaktadır.
\end{abstract}

Anahtar Kelimeler: Karadeniz Ekonomik İşbirliği Örgütü, Enerji, Panel Nedensellik

\section{Abstract \\ The Organization of Black Sea Economic Cooperation was established in 1992 under the leadership of Tur- key. The organization with twelve members mainly aspires to accelerate economical and political relations}

in global and regional levels. Analysis of the relationship between economic growth and energy, one of the main inputs of industry sector in these countries which are on the energy zone and corridor, affects applicable energy policies. In this paper, relationship between economic growth and energy consumption for the member counties of the Black Sea Economic Cooperation has been analyzed by panel causality method. In this sense, panel SUR causality test, counting both dependency of cross section and heteroscedasticity, and developed by Konya (2006), has been used. In this study, annual reel GDP per capita and energy consumption per capita data sets, obtaining from World Bank database WDI, have been used. Data covers the period of 1992-2011.

Keywords: Black Sea Economic Cooperation, Energy, Panel Causality

\section{Giriş}

Son ylllarda, sermaye ve emek gibi üretim faktörlerinin yanı sıra toplumların kişi başına ürettiği ve tükettiği enerji miktarı da iktisadi büyümenin ve gelişmişliğin göstergelerinden biri olarak kabul edilmektedir. Bir ekonomide enerji tüketimi ile ekonomik büyüme arasındaki ilişkinin sağlıklı bir şekilde analiz edilmesi, uygulanacak pek çok politikada karar almayı kolaylaştıracaktır. Çünkü enerji tüketimi ile ekonomik büyüme ilişkisi ticaret, enerji, çevre, kentleşme,

Yrd. Doç. Dr. Zafer Öztürk, Bülent Ecevit Üniversitesi İ̈BF, zaferozturk@beun.edu.tr Arş. Grv. Damla Öz, Bülent Ecevit Üniversitesi İİBF, damlaoz88@gmail.com

* Bu çalışma 3-5 Eylül 2014 tarihinde gerçekleştirilen I. Karadeniz ve Balkan Ekonomik ve Politik Araştırmalar Sempozyumu’nda sunulan bildirinin genişletilmiş halidir. 
istihdam ve finans politikaları gibi birçok alanda uygulanacak politikaların belirlenmesinde yol gösterici olacaktır.

Dünyanın enerji alanında önemli üretici ve tüketici ülkeleri Karadeniz Ekonomik İşbirliği Örgütü (KEİÖ) çatısı altında toplanmıştır. 25 Haziran 1992'de Türkiye’nin ev sahipliğinde ve 11 ülkenin ${ }^{1}$ katılımı ile Karadeniz Ekonomi İşbirliği Antlaşması imzalanmış, 1 Mayıs 1999'da örgüt niteliğine kavuşmuştur. KEIÖ’nün amaçları arasında Karadenize kıyısı olan ülkeler arasında serbest ticaret bölgesi oluşturulmas1, ekonomik işbirliğinin ve sosyal ilişkilerin geliştirilmesi, bölge güvenliğine yönelik tedbir alınması ve Karadeniz havzasının barış ve refah bölgesi olması yer almaktadır. KEİÖ bünyesinde enerji konusu da dâhil 18 adet çalışma grubu bulunmaktadır (Ardıl, 2013, s.454).

KEİÖ ülkelerinin bu çalışmaya konu olma nedeni, üye ülkeler arasındaki ekonomik işbirliği ve bölgenin enerji politikaları açısından kilit bir coğrafyada bulunmasıdır. KEİÖ, Körfez'den sonra dünyadaki en geniş petrol yataklarına sahip bölgede kuruludur. Hazar havzasındaki 200 milyar varil düzeyinde petrol yatağının yanı sıra dünya doğal gaz rezervinin de yaklaşık olarak \%27'si bu bölgede bulunmaktadır. KEİÖ'nün önemi, hem kapsadığı coğrafi alanda önemli miktarda petrol ve doğal gaz yataklarına sahip olmasından hem de özellikle Avrupa’ya yönelik enerji nakil yollarının topraklarının üzerinden geçmesinden kaynaklanmaktadır (Erkmenoğlu, 2001).

Enerji, özellikle gelişmekte olan ülkelerde son yıllarda kullanımı en çok artan üretim faktörüdür. Birçok ülkede enerji tüketimi ve ekonomik büyüme arasındaki ilişkiyi araştıran çalışmaların sayısı 1970'lerde yaşanan krizden sonra hızla artmıştır. Çünkü 1970’lerde yaşanan krizde artan petrol fiyatları pek çok ülkede negatif büyüme oranlarının görünmesine neden olmuştur. Her ne kadar literatürde yer alan ampirik çalışmalarda enerji tüketimi ve ekonomik büyüme arasındaki ilişkinin yönü ya da bu iki değişken arasında

1 KEI’nin kuruluş sürecini başlatan ülkeler Türkiye, Romana ya ve Bulgaristan'dır. Rusya, Ukrayna, Azerbaycan, Moldova, Gürcistan ve Ermenistan kurucu üye sıfatıyla katılmışlardır. Daha sonra Karadeniz'de kıyısı olmayan Yunanistan ve Arnavutluk kurucu üye olarak katılmıştır. 2004 yılında Sırbistan’n da katılmasıyla üye sayısı 12'ye ulaşmıștır (Ardıl, 2013, s.455). herhangi bir nedensellik ilişkisinin olup olmadığ 1 konusunda bir konsensüse varılamamış olsa da enerji tüketimi ve ekonomik büyüme arasındaki ilişkinin araştırılması, ülkelerin hem enerji politikasına hem de enerji tüketimi ve büyüme ilişkisi ile ilgili yukarıda bahsedilen diğer politikalara yön vermeleri açısından da oldukça önemlidir.

Ekonomik büyüme, geçmişten günümüze tüm ülkeler için en önemli makroekonomik göstergedir. 1950’lerde geliştirilen neoklasik büyüme modelleri teknolojiyi dışsal olarak kabul ederek üretim fonksiyonunda sadece emek ve sermaye faktörlerine yer vermiştir. Solow'un 1956 yılında yaptığı çalışmada üretim fonksiyonu şu şekildedir:

$$
Y=A(t) F(K, L) \text { ve } F(K, L)=L^{\beta} K^{1-\beta}
$$

(1) no.lu fonksiyonda A teknoloji, K sermaye ve L emek faktörünü temsil etmektedir. Modelde teknolojik değişimin büyümeyi etkilemekte olduğu ancak bu değişimin dişsal olarak gerçekleştiği kabul edilmektedir (Solow, 1956). İlerleyen ylllarda toprağın ve petrolün de üretim faktörü olarak fonksiyona dâhil edildiği Solow modelleri geliştirilmiş olmasına karşın enerji dikkate alınmamıştır (Sorensen, 2005, s.131).

Son ylllarda ise toplumların kişi başına ürettiği ve tükettiği enerji miktarı da iktisadi büyümenin ve gelişmişliğin göstergelerinden biri olarak kabul edilmekte ve büyüme modellerine dahil edilmektedir. 2010 y1lında Stern, Solow'un büyüme modeline enerji faktörünü ekleyerek yeni bir üretim fonksiyonu geliştirmiştir (Stern, 2010, s.17) :

$Y=\left[(1-\gamma)\left(A_{l}^{\beta} L^{\beta} K^{1-\beta}\right)^{\varphi}+\gamma\left(A_{E} E\right)^{\varphi}\right]^{1}$

(2) no.lu denklemde Solow'un 1956 yilında kulland1ğ Cobb-Douglas üretim fonksiyonu ile enerjinin yer aldığı CES fonksiyonu birleştirilip toplam çıktı fonksiyonu elde edilmiştir. Yeni modelde $\varphi=\frac{\sigma-1}{\sigma}$ olup, $\sigma$ enerjinin diğer faktörlere ikame esnekliğini göstermektedir. $\gamma$ ise enerjinin diğer girdilere göre önemini gösteren bir parametredir. $A_{E}$ ve $A_{1}$ teknolojik değişimin yaratacağ 1 enerji ve emek artış endeksidir.

Sermaye birikim fonksiyonu ise şu şekildedir: 
$\Delta K=s\left(Y-p_{E} E\right)-\delta K$

(3) no.lu denklemde $P_{E}$ enerji fiyatını ve $\delta$ sermayenin yıpranma payını göstermektedir.

İkame esnekliği $(\sigma)$ l'e ve önem parametresi $(\gamma)$ 0'a yaklaştıkça emeğin verimliliğini arttıran Solow modeline ulaşılmaktadır. Veri ikame esnekliğinde, enerji aşırı bol ise sermaye ve çıktının durağan durum düzeyi orijinal Solow modelindeki değişkenlerce belirlenir. Ancak enerji görece kıt faktör ise durağan durum düzeyi enerji arzına ve enerjinin verimliliğini arttırıcı teknolojiye bağlı olmaktadır (Stern, 2010, s.17-18).

Literatürde enerji tüketimi ile ekonomik büyüme arasindaki nedensellik ilişkisine dair dört hipotez bulunmaktadır (Apergis ve Payne, 2009, s.642):

1. Büyüme hipotezi (Growth hypothesis): Bu hipoteze göre, enerji tüketimi ekonomik büyümenin Granger nedenidir. Yani enerji tüketiminden ekonomik büyümeye doğru tek taraflı nedensellik ilişkisi vardır ve bu da o ülke ekonomisinin enerjiye bağımlı olduğunu göstermektedir. Dolayısıyla enerji tüketimindeki her bir değişiklik, o ülkenin GSYH'na yansiyacaktır.

2. Koruma hipotezi (Conservation hypoyhesis): $\mathrm{Bu}$ hipoteze göre, ekonomik büyümeden enerji tüketimine doğru tek taraflı nedensellik ilişkisi vardır. Bu da o ülkenin ekonomik büyümeyi gerçekleştirebilmek için enerji tüketimine bağımlı olmadığı anlamına gelmektedir. Aksine ekonomi geliştikçe enerji talebi artışı olacaktır.

3. Geribesleme hipotezi (Feedback hypothesis): Bu hipoteze göre, enerji tüketimi ve ekonomik büyüme arasında çift yönlü nedensellik ilişkisi vardır. Bu iki değişkendeki artış ya da azalış birbirini etkileyecektir.

4. Nötralite hipotezi (Neutrality hypothesis): $\mathrm{Bu}$ hipoteze göre, enerji tüketimi ve ekonomik büyüme arasında herhangi bir nedensellik ilişkisi bulunmamaktadır. Dolayısıyla ülkelerin enerji politikaları, onların iktisadi büyümeleri üzerinde etki yaratmayacaktır.

Bu çalışma 1992-2011 dönemi için Karadeniz Ekonomi İşbirliği Örgütüne üye 12 ülkede enerji tüketimi ve ekonomik büyüme arasındaki nedensellik ilişkisini araştırmaktadır. Çalışmada, enerji tüketimi ile ekonomik büyüme arasındaki nedensellik ilişkisi ortaya konularak politika yapıcılara, uygulanacak enerji politikaları hakkında fikir vermek amaçlanmaktadır. Bu bağlamda, Konya (2006) tarafından geliştirilen ve görünürde ilişkisiz regresyon tahminine dayalı panel nedensellik testi kullanılmıştır.

Çalışma dört bölümden oluşmaktadır. Birinci bölüm, teorik literatürün ve çalışma amacının kısaca ele alındığı giriş bölümüdür. Çalışmanın ikinci bölümünde, analize konu olan iki değişken arasındaki ilişkiyi inceleyen önceki çalışmalar derlenmiş ve ampirik literatür oluşturulmuştur. Üçüncü bölümde yatay kesit bağımlılı̆̆ı testi, eğim homojenite testi ve panel nedensellik testinden oluşan metodoloji kısmı yer almaktadır. Çalışmanın dördüncü ve son bölümünde ise uygulama sonuçları yorumlanmış ve sözü geçen ülkeler için politika önerilerine yer verilmiştir.

\section{Ampirik Literatür}

Enerji tüketimi ve büyüme arasındaki ilişkiyi inceleyen ilk çalışma Kraft ve Kraft (1978) tarafından ABD’nin yıllık verileri kullanılarak yapılmıştır. 19471974 yıllarını kapsayan ve Sims metodunu kullanan çalışmada gayri safi milli hâsıladan enerji tüketimine doğru tek taraflı nedensellik ilişkisi bulunmuştur. Sözü geçen çalışmadan iki yll sonra Akarca ve Long (1980) 1950-1970 dönemini ve altı yıl sonra da Yu ve Hwang (1984) 1947-1979 yıllarını kapsayan çalışmalarında yine ABD için aynı değişkenleri aynı metotla analiz etmiş ancak herhangi bir nedensellik ilişkisi bulamamışlardır.

Erol ve Yu (1987) ise Sims metodunu kullanarak 1952-1982 yılları için altı ülkeyi test etmiştir. Japonya için iki taraflı nedensellik ilişkisi, İtalya ve Almanya için büyümeden enerji tüketimine doğru tek taraflı nedensellik ilişkisi, Kanada için enerji tüketiminden iktisadi büyümeye doğru tek taraflı nedensellik ilişkisi bulurken, Fransa ve İngiltere için herhangi bir nedensellik ilişkisine ulaşmamışlardır. Nachane vd. (1988) içinde İtalya, İngiltere, Fransa ve Japonya’nın da olduğu 16 ülke için kointegrasyon analizi yapmış ve çift taraflı nedensellik ilişkisi olduğu sonucuna varmıştır.

Masih ve Masih (1996) yaptıkları çalışmada 19551991 dönemi için kointegrasyon analiziyle altı ülkeyi test etmiştir. Bu çalışmada da Hindistan'da enerji tüketiminden büyümeye doğru, Endonezyàda büyü- 
meden enerji tüketimine doğru tek taraflı nedensellik ilişkisi olduğu ve Malezya, Filipinler ve Singapur için iki değişken arasında nedensellik ilişkisi olmadığ sonucuna ulaşmışlardır.

Literatürde enerji tüketimi ve ekonomik büyüme arasındaki ilişkiyi Karadeniz Ekonomik İşbirliği Örgütü üyesi ülkeler için analiz eden bir çalışma bulunmamaktadır. Ancak söz konusu ülkeleri ayrı ayrı inceleyen çalışmalar 2000'li yıllarda başlamıştır.

Türkiye'de enerji tüketimi ve büyüme arasındaki ilişkiyi inceleyen çok sayıda çalışma vardır. Bunlardan ilki Asafu-Adjaye'nin (2000) 1971-1995 yıllarını kapsayan ve Türkiye'nin de içinde olduğu beş ülkeyi inceleyen çalışmasıdır. Kointegrasyon analizinin kullanıldığı çalışmada Türkiye, Hindistan ve Endonezya'da enerji tüketiminden ekonomik büyümeye doğru tek taraflı nedensellik ilişkisi olduğu sonucuna ulaşılmıştır. Soytaş vd. (2001) ise aynı metotla Türkiye'de 19601995 zaman aralığ için enerji tüketiminden kişi başı gelire doğru tek taraflı nedensellik ilişkisi bulurken, Altınay ve Karagöl (2004) Hsiao tarafından geliştirilen Granger nedensellik metoduyla 1950-2000 dönemi için iki değişken arasında herhangi bir nedensellik ilişkisi bulamamıştır. Benzer şekilde Jobert ve Karanfil (2007) 1960-2003 yıllarını kapsayan çalışmasında, Karanfil (2008) 1970-2005 dönemi için, Soytaş ve Sarı (2009) ise 1960-2000 dönemi için uyguladıkları Toda Yamamoto testinde değişkenler arasında nedensellik ilişkisi olmadığı sonucuna varmışlardır.

Hondroyiannis vd. (2002) Yunanistan'da enerji tüketimi ve GSYH arasındaki ilişkiyi inceleyen çalışmalarında 1960-1996 dönemi için değişkenler arasında çift taraflı nedensellik ilişkisi bulmuştur. Lee ise (2005) yılında aynı metotla 18 tane gelişmekte olan ülkeyi incelemiş ve bunlar için enerji tüketiminden ekonomik büyümeye doğru tek taraflı nedensellik ilişkisi olduğu sonucuna varmıştır.

Apergis ve Payne (2009) panel kointegrasyon analizi kullanarak içlerinde Ermenistan, Azerbaycan, Gürcistan, Rusya ve Ukrayna’nın da olduğu 11 ülke için kısa dönemde enerji tüketiminden büyümeye tek taraflı nedensellik, uzun dönemde iki yönlü nedensellik ilişkisi olduğunu tespit etmiştir. Öztürk ve Acaravc1 (2010) ARDL sinır testi ile Arnavutluk, Bulgaristan ve Romanya ülkeleri için enerji tüketimi ve ekonomik büyüme arasında nedensellik ilişkisi bulamaz- ken, Macaristan için iki değişken arasında çift yönlü nedensellik ilişkisi bulmuştur. Tsani (2010) ise Toda Yamamoto modeli ile Yunanistan'da enerji tüketiminden GSYH'ya doğru tek taraflı nedensellik ilişkisi olduğu sonucuna varmıştır.

Akkemik ve Göksal (2012) 79 ülke için Hurlin ve Venet tarafından geliştirilen panel nedensellik modelini kullanmış, aralarında Türkiye, Yunanistan, Bulgaristan, Moldova, Romanya, Rusya ve Ukrayna’nın da olduğu 57 ülkede enerji tüketimi ve GSYH arasında çift yönlü nedensellik ilişkisi olduğu sonucuna varmıștır. Kalyoncu vd. (2013) 1995-2009 yıllarını kapsayan çalışmasında Engle Granger kointegrasyon analizi kullanmış, Gürcistan ve Azerbaycan için enerji tüketimi ve kişi başı gelir arasında nedensellik ilişkisi olmad1ğını, Ermenistan için ise enerji tüketiminden kişi başı gelire doğru tek taraflı nedensellik ilişkisi olduğunu tespit etmiştir.

Bu çalışmada kullanılan Konyảnın panel nedensellik modeli ise enerji alanında ilk olarak Nazlığlu vd. (2011) tarafından 14 ülke için ekonomik büyüme ve nükleer enerji tüketimi arasındaki ilişkiyi inceleyen çalışmada kullanılmıştır. Aynı metotla Cowan vd. (2014) BRICS ülkelerinde 1990-2010 yılları için ve Wolde-Rufael (2014) ise 1975-2010 dönemi için 15 ülkede elektrik tüketimi ve ekonomik büyüme ilişkisini incelemiştir. Smiech ve Papiez (2014) yine Konya’nın metoduyla 25 ülke için enerji tüketimi ve kişi başı gelir arasındaki ilişkiyi incelemiş, 17 ülkede sözü geçen değişkenler ilişkisiz çıkarken, içinde Romanyảnın da bulunduğu dört ülkede kişi başı gelirden enerji tüketimine doğru tek taraflı nedensellik, Polonya ve Yunanistan'da enerji tüketiminden kişi başı gelire doğru tek taraflı nedensellik, Letonya ve Bulgaristan'da ise değişkenler arasında iki yönlü nedensellik ilişkisi tespit edilmiştir.

Josheski vd. (2014) Engle Granger kointegrasyon analizi kullanarak dört ülke için enerji tüketimi ve GSYH arasındaki ilişkiyi incelemiş, Arnavutluk, Bosna Hersek ve Sırbistan ülkeleri için nedensellik ilişkisi bulamamış, Makedonya için çift taraflı nedensellik ilişkisi bulmuştur.

Ampirik literatür Tablo 1'de özetlenmiş olup, adı geçen tüm çalışmalarda değişkenler yıllık verilerle analiz edilmiştir. 
Tablo 1. Enerji Tüketimi ve Ekonomik Büyüme Arasındaki Nedensellik illişkisini Ele Alan Çalışmalar

\begin{tabular}{|c|c|c|c|c|}
\hline Yazar(lar) & Metot & $\begin{array}{l}\text { Zaman } \\
\text { aralığı }\end{array}$ & Ülke(ler) & Sonuç \\
\hline Kraft ve Kraft (1978) & $\begin{array}{l}\text { Sims metodu ile } \\
\text { Granger nedensellik }\end{array}$ & $1947-1974$ & $\mathrm{ABD}$ & $\mathrm{G} \rightarrow \mathrm{E}$ \\
\hline $\begin{array}{l}\text { Akarca ve Long } \\
(1980)\end{array}$ & $\begin{array}{l}\text { Sims metodu ile } \\
\text { Granger nedensellik }\end{array}$ & $1950-1970$ & $\mathrm{ABD}$ & $\mathrm{G} \sim \mathrm{E}$ \\
\hline Yu ve Hwang (1984) & $\begin{array}{l}\text { Sims metodu ile } \\
\text { Granger nedensellik }\end{array}$ & $1947-1979$ & $\mathrm{ABD}$ & $\mathrm{G} \sim \mathrm{E}$ \\
\hline Erol ve Yu (1987) & $\begin{array}{l}\text { Sims metodu ile } \\
\text { Granger nedensellik }\end{array}$ & $1952-1982$ & $\begin{array}{l}\text { Japonya } \\
\text { İtalya ve Almanya } \\
\text { Kanada } \\
\text { Fransa ve İngiltere }\end{array}$ & $\begin{array}{l}\mathrm{E} \leftrightarrow \mathrm{G} \\
\mathrm{G} \rightarrow \mathrm{E} \\
\mathrm{E} \rightarrow \mathrm{G} \\
\mathrm{E} \sim \mathrm{G}\end{array}$ \\
\hline Nachane vd. (1988) & $\begin{array}{l}\text { Kointegrasyon, Hata } \\
\text { düzeltme modeli }\end{array}$ & $1950-1985$ & 16 ülke & $\mathrm{E} \leftrightarrow \mathrm{G}$ \\
\hline $\begin{array}{l}\text { Masih ve Masih } \\
\text { (1996) }\end{array}$ & $\begin{array}{l}\text { Kointegrasyon, Granger } \\
\text { nedensellik }\end{array}$ & 1955-1991 & $\begin{array}{l}\text { Hindistan } \\
\text { Endonezya } \\
\text { Pakistan } \\
\text { Malezya, Filipinler ve } \\
\text { Singapur } \\
\end{array}$ & $\begin{array}{l}\mathrm{E} \rightarrow \mathrm{G} \\
\mathrm{G} \rightarrow \mathrm{E} \\
\mathrm{E} \leftrightarrow \mathrm{G} \\
\mathrm{E} \sim \mathrm{G}\end{array}$ \\
\hline Asafu-Adjaye (2000) & $\begin{array}{l}\text { Kointegrasyon, Hata } \\
\text { düzeltme modeli }\end{array}$ & 1971-1995 & $\begin{array}{l}\text { Filipinler ve Tayland } \\
\text { Hindistan, Endonezya ve } \\
\text { Türkiye }\end{array}$ & $\begin{array}{l}\mathrm{E} \leftrightarrow \mathrm{G} \\
\mathrm{E} \rightarrow \mathrm{G}\end{array}$ \\
\hline Soytas vd. (2001) & $\begin{array}{l}\text { Kointegrasyon, Granger } \\
\text { nedensellik }\end{array}$ & $1960-1995$ & Türkiye & $\mathrm{E} \rightarrow \mathrm{G}$ \\
\hline $\begin{array}{l}\text { Hondroyiannis vd. } \\
\text { (2002) }\end{array}$ & Hata Düzeltme Modeli & 1960-1996 & Yunanistan & $\mathrm{E} \leftrightarrow \mathrm{G}$ \\
\hline $\begin{array}{l}\text { Altınay ve Karagöl } \\
(2004)\end{array}$ & $\begin{array}{l}\text { Granger nedensellik } \\
\text { (Hsiao'nun metodu) }\end{array}$ & $1950-2000$ & Türkiye & $\mathrm{E} \sim \mathrm{G}$ \\
\hline Lee (2005) & $\begin{array}{l}\text { Panel Kointegrason, } \\
\text { Hata Düzeltme Modeli }\end{array}$ & $1975-2001$ & 18 gelişmekte olan ülke & $\mathrm{E} \rightarrow \mathrm{G}$ \\
\hline $\begin{array}{l}\text { Jobert ve Karanfil } \\
(2007)\end{array}$ & Granger nedensellik & $1960-2003$ & Türkiye & $\mathrm{E} \sim \mathrm{G}$ \\
\hline Karanfil (2008) & $\begin{array}{l}\text { Granger nedensellik, } \\
\text { Kointegrasyon test }\end{array}$ & $1970-2005$ & Türkiye & $\mathrm{E} \sim \mathrm{G}$ \\
\hline Soytaş ve Sarı (2009) & $\begin{array}{l}\text { Toda Yamamoto } \\
\text { nedensellik testi }\end{array}$ & $1960-2000$ & Türkiye & $\mathrm{E} \sim \mathrm{G}$ \\
\hline $\begin{array}{l}\text { Apergis ve Payne } \\
(2009)\end{array}$ & $\begin{array}{l}\text { Panel Kointegrason, } \\
\text { Hata Düzeltme Modeli }\end{array}$ & $1991-2005$ & $\begin{array}{l}\text { Bağımsız Devletler Topluluğu } \\
\text { (11 ülke) }\end{array}$ & $\begin{array}{l}\mathrm{E} \rightarrow \mathrm{G} \text { (K1sa dönem) } \\
\mathrm{E} \leftrightarrow \mathrm{G} \text { (Uzun dönem) }\end{array}$ \\
\hline $\begin{array}{l}\text { Öztürk ve Acaravcı } \\
(2010)\end{array}$ & $\begin{array}{l}\text { ARDL Sinır Testi, } \\
\text { Kointegrasyon }\end{array}$ & $1980-2006$ & $\begin{array}{l}\text { Arnavutluk, Romanya ve } \\
\text { Bulgaristan } \\
\text { Macaristan }\end{array}$ & $\begin{array}{l}\mathrm{E} \sim \mathrm{G} \\
\mathrm{E} \leftrightarrow \mathrm{G}\end{array}$ \\
\hline Tsani (2010) & $\begin{array}{l}\text { Toda Yamamoto } \\
\text { nedensellik testi }\end{array}$ & $1960-2006$ & Yunanistan & $\mathrm{E} \rightarrow \mathrm{G}$ \\
\hline Nazlıoğlu vd. (2011) & $\begin{array}{l}\text { Panel nedensellik } \\
\text { (Konya'nın metodu) }\end{array}$ & $1980-2007$ & $\begin{array}{l}\text { Belçika, Kanada, Finalandiya, } \\
\text { Fransa, Almanya, Japonya, } \\
\text { Kore, Hollanda, İspanya, } \\
\text { İsveç, İsviçre ve ABD } \\
\text { Macaristan } \\
\text { İngiltere }\end{array}$ & $\begin{array}{l}\mathrm{NE} \sim \mathrm{G} \\
\mathrm{G} \rightarrow \mathrm{NE} \\
\mathrm{NE} \rightarrow \mathrm{G}\end{array}$ \\
\hline $\begin{array}{l}\text { Akkemik ve Göksal } \\
(2012)\end{array}$ & $\begin{array}{l}\text { Panel nedensellik } \\
\text { (Hurlin ve Venet'in } \\
\text { metodu) }\end{array}$ & $1980-2007$ & $\begin{array}{l}79 \text { ülke: } \\
7 \text { ülke } \\
9 \text { ülke } \\
6 \text { ülke } \\
57 \text { ülke }\end{array}$ & $\begin{array}{l}\mathrm{E} \sim \mathrm{G} \\
\mathrm{G} \rightarrow \mathrm{E} \\
\mathrm{E} \rightarrow \mathrm{G} \\
\mathrm{E} \leftrightarrow \mathrm{G}\end{array}$ \\
\hline Kalyoncu vd. (2013) & $\begin{array}{l}\text { Engle Granger } \\
\text { Kointegrasyon, Granger } \\
\text { nedensellik }\end{array}$ & $1995-2009$ & $\begin{array}{l}\text { Gürcistan ve Azerbaycan } \\
\text { Ermenistan }\end{array}$ & $\begin{array}{l}\mathrm{E} \sim \mathrm{G} \\
\mathrm{G} \rightarrow \mathrm{E}\end{array}$ \\
\hline
\end{tabular}


Tablo 1. Enerji Tüketimi ve Ekonomik Büyüme Arasındaki Nedensellik ilişkisini Ele Alan Çalışmalar

\begin{tabular}{|c|c|c|c|c|}
\hline Cowan vd. (2014) & $\begin{array}{l}\text { Panel nedensellik } \\
\text { (Konya'nın metodu) }\end{array}$ & $1990-2010$ & $\begin{array}{l}\text { Brezilya, Hindistan ve Çin } \\
\text { Rusya } \\
\text { Güney Afrika }\end{array}$ & $\begin{array}{l}\mathrm{EL} \sim \mathrm{G} \\
\mathrm{EL} \leftrightarrow \mathrm{G} \\
\mathrm{G} \rightarrow \mathrm{EL}\end{array}$ \\
\hline Wolde-Rufael (2014) & $\begin{array}{l}\text { Panel nedensellik } \\
\text { (Konya'nın metodu) }\end{array}$ & $1975-2010$ & $\begin{array}{l}15 \text { ülke: } \\
8 \text { ülke } \\
2 \text { ülke } \\
4 \text { ülke } \\
1 \text { ülke }\end{array}$ & $\begin{array}{l}\mathrm{EL} \sim \mathrm{G} \\
\mathrm{EL} \rightarrow \mathrm{G} \\
\mathrm{G} \rightarrow \mathrm{EL} \\
\mathrm{EL} \leftrightarrow \mathrm{G}\end{array}$ \\
\hline $\begin{array}{l}\text { Śmiech ve Papież } \\
\text { (2014) }\end{array}$ & $\begin{array}{l}\text { Panel nedensellik } \\
\text { (Konya'nın metodu) }\end{array}$ & 1993-2011 & $\begin{array}{l}25 \text { AB üyesi ülke: } \\
17 \text { ülke } \\
4 \text { ülke } \\
2 \text { ülke } \\
2 \text { ülke }\end{array}$ & $\begin{array}{l}\mathrm{E} \sim \mathrm{G} \\
\mathrm{G} \rightarrow \mathrm{E} \\
\mathrm{E} \rightarrow \mathrm{G} \\
\mathrm{E} \leftrightarrow \mathrm{G}\end{array}$ \\
\hline Josheski vd. (2014) & $\begin{array}{l}\text { EG Kointegrasyon, } \\
\text { Hata düzeltme modeli }\end{array}$ & - & $\begin{array}{l}\text { Arnavutluk, Bosna Hersek ve } \\
\text { Sirbistan } \\
\text { Makedonya }\end{array}$ & $\begin{array}{l}\mathrm{E} \sim \mathrm{G} \\
\mathrm{E} \leftrightarrow \mathrm{G}\end{array}$ \\
\hline
\end{tabular}

Not: E kişi başı enerji tüketimini, EL elektrik tüketimini, NE nükleer enerji tüketimini, G kişi başı geliri, nedensellik ilişkisi olmadığını, $\rightarrow$ tek taraflı nedensellik ilişkisini, $\leftrightarrow$ çift yönlü nedensellik ilişkisini temsil etmektedir.

\section{Veri ve Metodoloji}

Bu çalışmada Karadeniz Ekonomi İşbirliği Örgütü üyesi 12 ülkeye ait enerji tüketimi ve kişi başı reel gelir arasındaki ilişkiyi incelemek için değişkenlerin yıllık verileri kullanılmıştır. Analizde kişi başı toplam enerji tüketimi (lne) ve kişi başı reel GSYH (lng) değişkenlerinin logaritmik değerleri kullanılmıştır. Enerji tüketimi verisi kişi başı kg eşdeğer petrol ve kişi başı reel GSYH ise 2005 sabit dolar değeri üzerinden hesaplanmıştır. Tüm veriler 1992-2011 yıllarını kapsamaktadır ve Dünya Bankası web sayfasından elde edilmiştir (2014, WDI). Çalışmanın uygulama kısminda Stata 11, Gauss 9.0 ve TSP 5.0 programları kullanılmıştır.

Kullanılacak analiz yöntemini belirlemek için bazı ön testlere ihtiyaç bulunmaktadır. Bu nedenle ilk olarak yatay kesit bağımlılı̆̆ testi ve ardından da homojenlik testi yapılmıştır. Elde edilen sonuçlara göre panel nedensellik metodu belirlenmiştir.

\section{Yatay Kesit Bağımlılığı Testi}

Yatay kesit bağımlılı̆̆ testinin amacı, bir ülkeyi etkileyen bir şokun, diğer ülkelere yayılıp yayılmayacağını görmektir. Uluslararası serbestleşme ve küreselleşmenin etkisinin daha belirgin olduğu günümüzde bu test piyasalar açısından oldukça önemlidir. Söz konusu Karadeniz Ekonomi İşbirliği Örgütü üye ülkeleri için de bir araya geldikleri ortak paydadan yola çıka- rak bu testin çalışmamız açısından özellikle önemli olduğunu belirtmekte fayda vardır. Kaldı ki panel veri analizlerinde yatay kesit bağımlılığının dikkate alınmaması yanlı (biased) sonuçlar verebilmekte ve yaniltıcı olabilmektedir.

Yatay kesit bağımlılığı için Breusch ve Pagan (1980) ve Pesaran (2004) tarafından üç farklı test istatistiği geliştirilmiştir. Her bir test, farklı büyüklükteki yatay kesit ve zaman serisi boyutu için etkin kabul edilir.

Yatay kesit bağımlılığı testlerinin hipotezleri aşağıdaki gibidir:

$\mathrm{H}_{0}: \operatorname{Cov}\left(u_{i t}, u_{i j}\right)=0$ tüm $\mathrm{t}$ değerleri ve $\mathrm{i} \neq \mathrm{j}$ için,

$\mathrm{H}_{1}: \operatorname{Cov}\left(u_{i p} u_{i j}\right) \neq 0$ tüm $\mathrm{t}$ değerleri ve en az bir $\mathrm{i} \neq \mathrm{j}$ çifti için.

Yatay kesit bağımlılığı testi için Breusch ve Pagan (1980) (4) no.lu eşitlikte gösterilen Lagrange çarpanı istatistiğini önermişlerdir:

$\mathrm{CD}_{\mathrm{BP}}=\mathrm{T} \sum_{i=1}^{N-1} \sum_{j=i+1}^{N} \rho_{i j}^{2} \sim X_{N(N-1) / 2}^{2}$

(4) no.lu eşitlikte bireysel EKK tahminlerinden elde edilen hata terimleri arasinda tahmin edilen korelasyon katsayısıdır. Testin boş hipotezi yatay kesit bağımlılığının olmadığıdır. İstatistik, N(N-1)/2 serbestlik derecesi ile ki-kare asimptotik dağılımına sahiptir. Ancak bu test büyük yatay kesitler $(\mathrm{N})$ için uygun de- 
ğildir. Bu problemin üstesinden gelmek için Pesaran (2004) tarafından yeni bir Lagrange çarpanı istatistiği geliştirilmiştir:

$\mathrm{CD}_{\mathrm{LM}}=\left(\frac{1}{N(N-1)}\right) 1 / 2 \sum_{i=1}^{N-1} \sum_{j=i+1}^{N}\left(T \rho_{i j}^{2}-1\right) \sim N(0,1)$

(5) no.lu denklem "yatay kesit bağımlılı̆̆ı yoktur" boş hipotezi altında asimptotik Standard normal dağıllma sahiptir. Bu test istatistiği zaman serisi $(\mathrm{T})$ ve yatay kesit $(\mathrm{N})$ boyutu sonsuza giderken geçerlidir.

Pesaran (2004) zaman serisinin yatay kesitten daha küçük olduğu durumlarda yatay kesit bağımlılığı testi yapabilmek için (6) no.lu istatistiği geliştirmiştir:
$\mathrm{CD}_{\mathrm{LM} 1}=\sqrt{\frac{2 T}{N(N-1)}} \sum_{i=1}^{N-1} \sum_{j=i+1}^{N} \rho_{i j} \sim N(0,1)$

(6) no.lu denklem de "yatay kesit bağımlılığı yoktur" boş hipotezi altında asimptotik standart normal dağllıma sahiptir.

Tablo 2'de yatay kesit bağımlılı̆̆ı testinin sonuçları yer almaktadır. Üç farklı yatay kesit bağımlılığı testi de "bağımlılık yoktur" boş hipotezini \%1 anlamlılık düzeyinde reddetmektedir.

Tablo 2. Yatay Kesit Bağımlılığı Testi

\begin{tabular}{|l|l|l|}
\hline Test & Ístatistik & p-değeri \\
\hline $\mathrm{CD}_{\mathrm{BP}}$ & $1064.837^{*}$ & 0.000 \\
\hline $\mathrm{CD}_{\mathrm{LM}}$ & $32.516^{*}$ & 0.000 \\
\hline $\mathrm{CD}_{\mathrm{LM} 1}$ & $5.61^{*}$ & 0.000 \\
\hline * boş hipotez \% 1 anlamlılık düzeyinde reddedilmiştir. \\
\hline
\end{tabular}

Test sonuçları bize Karadeniz Ekonomi İşbirliği Örgütü üyesi ülkelerin bağımlı olduğunu, yani içlerinden birinde oluşacak bir şokun diğer üye ülkeleri de etkileyebileceğini göstermektedir.

\section{Eğim Homojenite Testi}

Ülkeler arasında bir bağımlılık olsa bile her ülkenin kendi dinamiklerini koruyup korumadığını görmek için homojenite testi yapılmalıdır. Homojenite testinin en bilindik yolu Wald prensibine dayalı standart F testidir. F testinin hipotezi şu şekildedir:

$H_{0}: \beta_{i}=\beta$ tüm i değerleri için (Eğim katsayıları homojendir)

$H_{0}: \beta_{i} \neq \beta \quad \mathrm{i} \neq \mathrm{j} \quad$ için (Eğim katsayıları homojen değildir)

F testi, yatay kesit boyutu N'nin görece küçük, zaman serisi boyutu T’nin görece büyük olduğunda ve değişen varyans problemi olmadığında geçerli olmaktadır. Swamy (1970) değişen varyans probleminin kısıt olmaktan çıktığı bir eğim homojenliği testi geliştirmiştir.

$\hat{S}=\sum_{i=1}^{N}\left(\hat{\beta}_{i}-\hat{\beta}_{W F E}\right)^{\prime} \frac{x_{i}^{\prime} I_{T} x_{i}}{\sigma^{2}}\left(\hat{\beta}_{i}-\hat{\beta}_{W F E}\right)$

(7) no.lu denklemde panel EKK tahmincisi, ağırlıklandırılmış sabit etki tahmincisi ve birim matristir.
Swamy test de tıpkı F testi gibi N’nin T’ye göre küçük olduğu paneller için geçerli kabul edilmektedir.

Pesaran ve Yamagata (2008), eğim homojenitesini geniş panellerde ölçmek için Swamy testinin standardize edilmiş versiyonunu (yani testini) geliştirmiştir. Test istatistiği şu şekildedir:

$\widetilde{\Xi}=\sqrt{N}\left(\frac{N^{-1} S-k}{\sqrt{2 k}}\right)$

(8) no.lu testin düzeltilmiş versiyonu ise diye adlandırılmış olup istatistiği aşağıda verilmiştir:

$\widetilde{\Xi}_{a d j}=\sqrt{N}\left(\frac{N^{-1} S-E\left(z_{i T}\right)}{\sqrt{\operatorname{Var}\left(z_{i T}\right)}}\right)$

Normalite varsayımı altında (9) no.lu denklem, yani testi küçük örneklemler için geliştirilmiştir.

Tablo 3'te homojenite testi sonuçları yer almaktadır. Üç farklı homojenite testi yapılmış olup, sadece Swamy testine göre "eğim homojendir" boş hipotezi $\% 1$ anlamlılık düzeyinde reddedilmiştir.

Çalışmamızda zaman serisi boyutu, yatay kesite göre daha büyük olduğu için ve üzerinde çalıştığımız veri geniş panel olmadığ için Pesaran ve Yamagata tarafından büyük paneller için geliştirilmiş Delta testle- 
Tablo 3. Homojenite Testi

\begin{tabular}{|l|l|}
\hline Test & İstatistik \\
\hline Delta Tilda & 0.993 \\
\hline Delta Tilda -adj & 1.073 \\
\hline Swamy & $713.531^{*}$ \\
& \\
\hline * boş hipotezin \%1 anlamlılık düzeyinde reddedildiğini gösterir. \\
\hline
\end{tabular}

ri bizim verilerimiz için sağlıklı sonuç vermeyebilir. Swamy test ise bizim çalışmamızda olduğu gibi küçük paneller için geçerli kabul edilmektedir. Dolayısıyla göz önünde bulundurmamız gereken sonuç Swamy testinin sonucudur. Bu teste göre eğim katsayılarının homojenliği reddedilmiştir.

\section{Panel Nedensellik Testi}

Granger’e (1969) göre, Granger nedensellik demek, bir değişkenin (X) geçmiş değerleri bilgisinin diğer bir değişkenin $(\mathrm{Y})$ gelecek değerlerinin şekillenmesine etki etmesi demektir. Ülkeler arasında yatay kesit bağımlılığı olması ve eğim katsayılarının heterojen olması, bu özelliklerle uygulanması mümkün olan bir nedensellik metodu kullanımını zorunlu kılar. Bu nedenle, Konya (2006) tarafından geliştirilen panel nedensellik yaklaşımı çalışmamız için en uygun modeldir. Bu metot, denklem kümesinin görünürde ilişkisiz regresyon (SUR) tahminine ve ülkelere özgü bootstrap kritik değerlerle sınanan Wald testine dayalı bir yaklaşımdır. Dolayısıyla değişkenlerin durağan olmalarını gerektirmez, değişkenler düzey değerleri ile analize katılabilirler. Bu sürecin bazı avantajları bulunmaktadır. Öncelikle test, panelin homojen olduğunu varsaymaz; böylece her bir panel üyesine ayrı ayrı Granger nedensellik testi yapmak mümkün hale gelir. İkincisi, bu yaklaşım kointegrasyon ya da birim kök testi gibi bir ön test gerektirmez, çünkü her bir ülke için ayrı bootstrap kritik değeri elde edilir. Son olarak da, bu metot araştırmacılara hangi panel üyelerinde tek taraflı Granger nedensellik, hangi panel üyelerinde çift yönlü Granger nedensellik olduğunu ve hangi üyelerde nedensellik ilişkisi olmadığını saptama imkanı verir (Afonso ve Rault, 2009).

İlk aşamada denklemler kümesi SUR metodu ile tahmin edilir. Sistem aşağıdaki gibidir:

$$
\begin{aligned}
& y_{1, t}=\alpha_{1,1}+\sum_{l=1}^{m l y_{1}} \beta_{1,1, l} y_{1, t-1}+\sum_{l=1}^{m l x_{1}} \gamma_{1,1, l} x_{1, t-1}+\varepsilon_{1,1, t} \\
& y_{2, t}=\alpha_{1,2}+\sum_{l=1}^{m l y_{1}} \beta_{1,2, l} y_{2, t-1}+\sum_{l=1}^{m l x_{1}} \gamma_{1,2, l} x_{2, t-1}+\varepsilon_{1,2, t} \\
& \vdots \\
& y_{N, t}=\alpha_{1, N}+\sum_{l=1}^{m l y_{1}} \beta_{1, N, l} y_{N, t-1}+\sum_{l=1}^{m l x_{1}} \gamma_{1, N, l} x_{N, t-1}+\varepsilon_{1, N, t} \\
& \text { ve } \\
& x_{1, t}=\alpha_{2,1}+\sum_{l=1}^{m l y_{2}} \beta_{2,1, l} y_{1, t-1}+\sum_{l=1}^{m l x_{2}} \gamma_{2,1, l} x_{1, t-1}+\varepsilon_{2,1, t} \\
& x_{2, t}=\alpha_{2,2}+\sum_{l=1}^{m l y_{2}} \beta_{2,2, l} y_{2, t-1}+\sum_{l=1}^{m l x_{2}} \gamma_{2,2, l} x_{2, t-1}+\varepsilon_{2,2, t} \\
& \vdots \\
& x_{N, t}=\alpha_{2, N}+\sum_{l=1}^{m l y_{2}} \beta_{2, N, l} y_{N, t-1}+\sum_{l=1}^{m l x_{2}} \gamma_{2, N, l} x_{N, t-1}+\varepsilon_{2, N, t}
\end{aligned}
$$

Bu çalışmada kullanılan değişkenler göz önüne alındığında, denklem kümesindeki $l$ gecikme sayısını, $y$ kişi başı reel GSYH'ı ve $x$ enerji tüketimini göstermektedir. Hata terimleri eşzamanlı olarak ilişkili iken (yani yatay kesit bağımlılığı varken) sistemdeki her bir denklem, önceden belirlenmiş (predetermined) farklı değişkenlere sahip olduğundan (10) ve (11) no.lu denklemler kümesi görünürde ilişkisiz regresyon (SUR) sistemidir.

Böyle bir panel nedensellik sisteminde her bir ülke için dört tane alternatif hipotez geliştirilebilir:

- Eğer tüm $\gamma_{1, i}$ değerleri sıfıra eşit değilse ve fakat tüm $\beta_{2, i}$ değerleri sıfıra eşitse, x'ten y'ye doğru tek taraflı Granger nedensellik ilişkisi vardır.

- Eğer tüm $\gamma_{1, i}$ değerleri sıfıra eşitse ve fakat tüm $\beta_{2, i}$ değerleri sıfıra eşit değilse, y'den x'e doğru tek taraflı Granger nedensellik ilişkisi vardır. 
- Eğer tüm $\gamma_{1, i}$ değerleri ve tüm $\beta_{2, i}$ değerleri sifira eşit değilse, $\mathrm{x}$ ve $\mathrm{y}$ arasında çift taraflı Granger nedensellik ilişkisi vardır.

- Eğer tüm $\gamma_{1, i}$ değerleri ve tüm $\beta_{2, i}$ değerleri sıfıra eşitse, $x$ ve y arasında Granger nedensellik ilişkisi yoktur.

$\mathrm{Bu}$ testte optimal gecikme sayısı, Schwarz Bayesian Kriterini minimum yapan 1 ile 4 arasındaki değer ile belirlenir (Konya, 2006).

Tablo 4'te panel nedensellik analizi sonuçları yer almaktadır.
Tablo 4'e göre, Ermenistan, Yunanistan ve Rusya'da enerji tüketimi ile kişi başı reel gelir arasında sırasıyla $\% 10, \% 5$ ve $\% 5$ anlamlılık düzeyinde çift yönlü nedensellik ilişkisi bulunmaktadır. Gürcistan'da ise enerji tüketimi, kişi başı reel gelirin Granger nedenidir, yani Gürcistan'da $\% 5$ anlamlllık düzeyinde enerji tüketiminden kişi başı gelire doğru tek taraflı nedensellik ilişkisi bulunmuştur. Buna karşın Arnavutluk, Azerbaycan, Bulgaristan, Moldova, Romanya, Sirbistan, Türkiye ve Ukrayna’da iki değişken arasında herhangi bir nedensellik ilişkisi bulunamamıştır.

Tablo 4. Panel Granger Nedensellik Analizi Sonuçları

\begin{tabular}{|c|c|c|c|c|c|c|c|c|}
\hline \multirow[t]{3}{*}{ Ülkeler } & \multicolumn{4}{|c|}{$\begin{array}{l}\mathrm{H}_{0}: \text { Ine, lng'nin Granger nedeni değildir } \\
\mathrm{H}_{1}: \mathrm{E} \rightarrow \mathrm{G}\end{array}$} & \multicolumn{4}{|c|}{$\begin{array}{l}\mathrm{H}_{0}: \operatorname{lng} \text {, lne'nin Granger nedeni değildir } \\
\mathrm{H}_{1}: \mathrm{G} \rightarrow \mathrm{E}\end{array}$} \\
\hline & \multirow[t]{2}{*}{ Wald test } & \multicolumn{3}{|c|}{ Bootstrap kritik değerleri } & \multirow[t]{2}{*}{ Wald test } & \multicolumn{3}{|c|}{ Bootstrap kritik değerleri } \\
\hline & & $\% 1$ & $\% 5$ & $\% 10$ & & $\% 1$ & $\% 5$ & $\% 10$ \\
\hline Arnavutluk & 0.116 & 41.792 & 19.337 & 12.045 & 5.013 & 86.888 & 39.896 & 26.093 \\
\hline Ermenistan & $26.635^{* * *}$ & 73.014 & 34.851 & 22.405 & 98.809* & 35.207 & 17.373 & 11.524 \\
\hline Azerbaycan & 17.675 & 51.229 & 26.875 & 18.202 & 0.001 & 38.784 & 19.883 & 13.107 \\
\hline Bulgaristan & 12.211 & 58.905 & 29.246 & 19.256 & 0.355 & 34.193 & 16.769 & 11.305 \\
\hline Gürcistan & $60.922^{* *}$ & 77.445 & 37.470 & 25.576 & 9.998 & 45.102 & 21.849 & 14.758 \\
\hline Yunanistan & 97.102* & 61.747 & 30.318 & 19.611 & $21.321^{* *}$ & 34.146 & 17.679 & 11.952 \\
\hline Moldova & 15.277 & 67.802 & 30.982 & 19.383 & 2.928 & 44.377 & 23.196 & 15.322 \\
\hline Romanya & 1.689 & 43.719 & 21.843 & 14.420 & 0.321 & 47.700 & 24.635 & 16.177 \\
\hline Rusya & $36.505^{* *}$ & 47.872 & 25.119 & 16.557 & $32.241^{* *}$ & 36.022 & 17.658 & 12.334 \\
\hline Sirbistan & 1.609 & 58.403 & 27.575 & 18.359 & 1.0592 & 42.256 & 19.846 & 13.165 \\
\hline Türkiye & 1.413 & 40.822 & 19.434 & 12.683 & 11.090 & 39.826 & 20.071 & 12.977 \\
\hline Ukrayna & 18.404 & 64.976 & 31.950 & 21.755 & 0.119 & 40.451 & 19.656 & 13.383 \\
\hline
\end{tabular}

*,** ve *** boş hipotezin sırasıyla \% 1,5 ve 10 anlamlılık düzeyinde reddedildiğini göstermektedir.

\section{Sonuç}

Bu çalışmada, KEİO üyesi 12 ülke için 1992-2011 yılları arasında enerji tüketimi ve ekonomik büyüme arasındaki nedensellik ilişkisi araştııılmıştır. Uygulamada ülkeler arasındaki bağımlılık ve eğim heterojenliği göz önünde bulundurularak Konya (2006) tarafından geliştirilen panel nedensellik metodu kullanılmıştır.

Panel Granger nedensellik analizi sonucunda Ermenistan, Yunanistan ve Rusya ülkeleri için geri besleme (feedback) hipotezinin geçerli olduğu sonucuna varılmıştır. Yunanistan ve Rusya için bulunan ilişki Hondroyiannis vd. (2002) ve Akkemik ve Göksal (2012) tarafından ulaşılan analiz sonuçları ile uyumlu iken Ermenistan için Apergis ve Payne (2009) ve Kalyoncu vd. (2013) tarafından varılan "enerji tüketiminden büyümeye doğru tek taraflı nedensellik iliş- kisi” sonucu ile farklılaşmaktadır. Çalışmalarda farklı metotlar kullanılmış olması bu durumun nedeni olabilir. Bu çalışmada elde edilen bulgulara göre Ermenistan, Yunanistan ve Rusya için enerji harcamaları ve GSYH birbirini karşılıklı olarak etkilemektedir. Bu ülkelerde GSYH artışı enerji tüketimini artıracak, artan bu enerji tüketimi ise ekonomik büyümeye neden olacaktır. Buna göre enerjiye iki yönlü bağımlılık gösteren bu ülkelerin, ihtiyaç duyduğu enerjiyi kendisi üretebilir konuma gelmesi ve bu bağlamda yenilenebilir enerji kaynaklarına yönelmesi büyük önem arz etmektedir.

Çalışmamızda Gürcistan için büyüme (growth) hipotezinin geçerli olduğu ve bu sonucun Akkemik ve Göksal (2012) tarafından yapılan araştırma ile uyumlu olduğu gözlenmektedir. Bu da Gürcistan’ın enerjiye bağımlı bir ülke olduğunu, dolayısıyla ülkenin enerji 
darboğazına düşmesinin ekonomik büyümeyi olumsuz etkileyeceğini göstermektedir. Ayrıca bu ülkede enerji harcamalarının azaltılmasını öngören politikalar da ekonomik büyümeyi olumsuz etkileyecektir.

Arnavutluk, Azerbaycan, Bulgaristan, Moldova, Romanya, Sırbistan, Türkiye ve Ukrayna için ise nötralite (neutrality) hipotezinin geçerli olduğu sonucuna ulaşılmıştır. Bu durum Arnavutluk, Azerbaycan, Türkiye, Sırbistan ve kısmen Bulgaristan ve Romanya için ampirik literatürle uyumlu ilişkiler bulduğumuza işaret etmektedir. Sonuç olarak KEİ ülkelerinin çoğuna (8 ülke) dair enerji tüketimi ve ekonomik büyümenin birbirinden bağımsız olduğu söylenebilmektedir. Yani bu ülkeler için enerji koruma politikaları, ekonomik büyüme üzerinde herhangi bir etkiye yol açmayacak ya da enerji tüketimi ekonomik performanstan etkilenmeyecektir. Bu durumda politika yapıcılar enerji politikalarını belirlerken o ülkedeki ekonomik faaliyetlere bağımlı kalmak zorunda değildirler.

\section{Kaynakça}

Afonso, A., Rault, C. (2009). Bootstrap Panel GrangerCausality between Government Budget and External Deficits for the EU. CESIFO Working Paper No. 2581. Erişim: http://papers.ssrn.com/sol3/papers. cfm?abstract_id=1360638.

Akarca, A.T., Long, T.V. (1980). On the Relationship between Energy and GDP: A Re-Examination. Journal of Energy Development. 5, 326-331.

Akkemik, K. A., Göksal, K. (2012). Energy Consumption - GDP Nexus: Heterogeneous Panel Causality Analysis. Energy Economics. 34, 865-873. doi:10.1016/j.eneco.2012.04.002.

Altinay, G., Karagöl, E. (2004). Structural Break, Unit Root, and the Causality between Energy Consumption and GDP In Turkey. Energy Economics, 26, 985-994. doi:10.1016/j.eneco.2004.07.001.

Apergis, N., Payne, J. E. (2009). Energy Consumption and Economic Growth: Evidence from the Commonwealth of Independent States. Energy Economics, 31(5), 641 - 647. doi:10.1016/j.eneco.2009.01.011.

Ardıl, C. (2013). Türkiye - Karadeniz Ekonomik İsbirliği Örgütü: 1996-2012 Dönemi Dış Ticaret İlişkileri. International Conference on Eurasian Economies 2013. Erişim: http://www.eecon.info/papers/661.pdf.
Asafu-Adjaye, J. (2000). The Relationship between Energy Consumption, Energy Prices and Economic Growth: Time Series Evidence from Asian Developing Countries. Energy Economics, 22, 615625. doi:10.1016/S0140-9883(00)00050-5.

Breusch, T., Pagan, A. (1980). The LM Test and its Application to Model Specification in Econometrics. Review of Economic Studies 47, 239-254.

Cowan, W. N., Chang, T., Inglesi-Lotz, R., Gupta, R. (2014). The Nexus of Electricity Consumption, Economic Growth and $\mathrm{CO}_{2}$ Emissions in the BRICS Countries. Energy Policy, 66, 359-368. Erişim: https:// ideas.repec.org/p/pre/wpaper/201340.html.

Erkmenoğlu, F. (2001). Karadeniz Ekonomik İşbirliği (KEİ) - Örgütünün Dünü, Bugünü ve Geleceği. Uluslararasi Ekonomik Sorunlar Dergisi, II. Erişim: http://www.mfa.gov.tr/karadeniz-ekonomikisbirlici-_kei_---orgutunun-dunu_-bugunu-vegelececi.tr.mfa.

Erol, U., Yu, E.S.H., (1987). On the Causal Relationship between Energy and Income for Industrialized Countries. Journal of Energy and Development 13, 113-122.

Granger, C. W. J. (1969). Investigating Causal Relations by Econometric Models and Cross-Spectral Methods. Econometrica, 37, 424-438.

Hondroyiannis, G., Lolos, S., Papapetrou, E. (2002). Energy Consumption and Economic Growth: Assessing the Evidence from Greece. Energy Economics, 24, 319-336. doi:10.1016/S01409883(02)00006-3.

Jobert, T., Karanfil, F. (2007). Sectoral Energy Consumption by Source and Economic Growth in Turkey. Energy Policy, 35(11), 5447-5456. Erişim: http://ecomod.net/sites/default/files/documentconference/ecomod2007-energy/117.pdf.

Josheski, D., Magdinceva-Sopova, M., Sovreski, Z. (2014). Energy Consumption, Economic Development and Prices: Time Series Evidence in CESEE Countries. Comparative Political Economy: Regulation eJournal. Erişim: http://papers.ssrn.com/sol3/ papers.cfm?abstract_id=2420112.

Kalyoncu, H., Gürsoy, F., Göcen, H. (2013). Causality Relationship between GDP and Energy Consumption in Georgia, Azerbaijan and Armenia. International Journal of Energy Economics and Policy, 3 (1), 111-117. 
Karanfil, F. (2008). Energy Consumption and Economic Growth Revisited: Does the Size of Unrecorded Economy Matter?. Enrgy Policy, 36(8), 30293035. doi:10.1016/j.enpol.2008.04.002.

Konya, L. (2006). Exports and Growth: Granger Causality Analysis on OECD Countries with a Panel Data Approach. Economic Modelling, 23, 978-992. doi:10.1016/j.econmod.2006.04.008.

Kraft, J., Kraft, A. (1978). On the Relationship between Energy and GNP. Journal of Energy Development, 3, 401-403.

Lee, C. C. (2005). Energy Consumption and GDP in Developing Countries: A Cointegrated Panel Analysis. Energy Economics, 27, 415-427. Erişim: http://www.sciencedirect.com/science/article/pii/ S014098830500023X.

Masih, A. M. M., Masih, R. (1996). Energy Consumption, Real Income and Temporal Causality: Results from a Multi-Country Study Based on Cointegration and Error-Correction Modeling Techniques, Energy Economics, 18 (3), 165-183.

Nachane, D.M., Nadkarni, N.M., Karnik, A.V., (1988). Co-integration and Causality Testing of the Energy GDP Relationship: A Cross-Country Study. Applied Economics, 20 (11), 1511-1531.

Nazlığlu S., Lebe F., Kayhan S. (2011). Nuclear Energy Consumption and Economic Growth in OECD Countries: Cross-Sectionally Dependent Heterogeneous Panel Causality Analysis. Energy Policy, 39, 6615-6621.

Öztürk, İ., Acaravcı, A. (2010). The Causal Relationship between Energy Consumption and GDP in Albania, Bulgaria, Hungary and Romania: Evidence from ARDL Bound Testing Approach. Applied Energy. 87, 1938-1943. Erişim: http://www.sciencedirect.com/ science/article/pii/S0306261909004383.

Pesaran, M. H. (2004). General Diagnostic Tests for Cross Section Dependence in Panels. IZA Discussion Paper 1240, Institute for the Study of Labor.

Pesaran, M.H., Yamagata, T. (2008). Testing Slope Homogeneity in Large Panels. Journal of Econometrics, 142, 50-93. doi:10.1016/j.jeconom.2007.05.010.

Śmiech, S., Papież, M. (2014). Energy Consumption and Economic Growth in the Light of Meeting the Targets of Energy Policy in the EU. 11th International Conference "European Energy Market", Kraków, Poland.
Solow, R.M. (1956). A Contribution to the Theory of Economic Growth. The Quarterly Journal of Economics, 70 (1), 65-94.

Sorensen P., Whitta-Jacobsen H. (2005). Introducing Advanced Macroeconomics. The McGrow-Hill Companies.

Soytas, U., Sari, R., Ozdemir, O. (2001). Energy Consumption and GDP Relation in Turkey: A Cointegration and Vector Error Correction Analysis. Economies and Business in Transition: Facilitating Competitiveness and Change in the Global Environment Proceedings, 838-844.

Soytaş, U., Sar1, R. (2009). Energy Consumption, Economic Growth, and Carbon Emissions: Challenges Faced by an EU Candidate Member. Ecological Economics, 68, 1667-1675. doi:10.1016/j.ecolecon.2007.06.014.

Stern, D. I. (2010). The Role of Energy in Economic Growth. CCEP Working Paper 3.10, Centre for Climate Economics \& Policy, Crawford School of Economics and Government, The Australian National University, Canberra.

Swamy, P. A. V. B. (1970). Efficient Inference in a Random Coefficient Regression Model. Econometrica, $38,311-323$.

Tsani, Z. S. (2010). Energy Consumption and Economic Growth: A Causality Analysis for Greece. Energy Economics. 32, 582-590. doi:10.1016/j.eneco.2009.09.007.

Wolde-Rufael, Y. (2014) Electricity Consumption and Economic Growth in Transition Countries: A Revisit Using Bootstrap Panel Granger Causality Analysis. Energy Economics, 44, 325-330. doi:10.1016/j.eneco.2014.04.019.

Worldbank. (2014). World Development Indicators. http://data.worldbank.org/data-catalog/worlddevelopment-indicators. Erişim tarihi: 20.06.2014.

Yu, E.S.H., Hwang, B.K., (1984). The Relationship between Energy and GNP: Further Results. Energy Economics 6, 186-190. doi:10.1016/01409883(84)90015-X. 